\title{
Perspectives for leprosy control and elimination
}

\author{
Perspectivas para o controle e eliminação da \\ hanseníase
}

Perspectivas para el control y eliminación de la lepra

Eliane Ignotti 1,2

Peter Steinmann 3,4

doi: 10.1590/0102-311X00170019

Recently, data and news about rising numbers of leprosy cases in some low endemic countries, as well as in certain areas of high-burden countries, have become prominent 1 . This increase leads us to reflect upon changes in transmission patterns and difficulties regarding interventions strategies for leprosy control.

Leprosy is classified as a neglected tropical disease (NTD) targeted for elimination 2. The goal of elimination as a public health problem was agreed upon by the Member States of the World Health Organization (WHO) in 19913 . Since the resolution, many countries have revised their leprosy strategies including a rigorous review and updating of databases, standardized declaration of cure upon multi-drug therapy (MDT) completion according to official protocols with reduced treatment time 4 etc. Additionally, countries invested considerable efforts in active case finding, including campaigns, decentralization of care, definition of priority areas for interventions and integration of activities with other NTDs ${ }^{5}$. More recently, integration with other chronic infectious diseases has also been explored 5. Of note, even Mycobacterium leprae transmission prediction models suggest that case detection needs to be increased to reduce disease burden and achieve reduced transmission 6 .

It is generally accepted that there are no sudden leprosy outbreaks due to the long incubation period and the slow evolution of the disease, which mean that the patients being diagnosed today were infected several years ago 7 . Consequently, changes in the trend of incidence indicators are slow, except for the effects of operational factors. In developing countries, active case finding efforts in vulnerable populations typically result in the detection of new patients, with the most vulnerable groups being the contacts of index patients, including domestic, neighbor and social contacts 8 , whose risk is dependent on proximity and contact duration, leprosy type of the index patient, and blood relationship. There is now also consensus that $M$. leprae circulate in the environment of endemic areas. This ecological component has recently been explored in more detail, but its epidemiological significance remains unclear ${ }^{9}$. Other etiological agents such as $M$. lepromatosis have also been described 10.

Treatment for leprosy has been made available for decades through the WHO to endemic countries, free of charge. Reported stock-outs of the medication are due to logistical issues. To complement the standard MDT, locally procured drugs are needed for special conditions, and to control so-called leprosy reactions.

To sum up, by "leprosy" we are referring to a historically endemic, treatable, and curable infectious disease. Therefore, the basic surveillance recommendations are to ensure early diagnosis and
1 Universidade do Estado de Mato Grosso, Cáceres, Brasil.

2 Universidade Federal de Mato Grosso, Cuiabá, Brasil.

3 Swiss Tropical and Public Health Institute, Basel, Switzerland.

4 University of Basel, Basel, Switzerland.

\section{Correspondence}

E. Ignotti

Universidade do Estado de Mato Grosso.

Av. Tancredo Neves 1095 Cáceres, MT 78200-000 Brasil.

eliane.ignotti@unemat.br 
prompt treatment, including through contact trancing to effectively search for new cases, reducing the chain of transmission. Furthermore, poor nutrition and living conditions have also been identified as determinants for leprosy, and recent studies have highlighted and quantified its association with poverty 11. Considering the current economic situation and prevalence of conflicts and associated large-scale and long-distance migration resulting in reduced income and deteriorating living conditions 12 , the number of leprosy cases is likely to increase in certain areas while the global aggregate might fall slowly and gradually. Thus, new technologies and approaches, including revised therapeutic protocols, pre- and post-exposure prophylaxis with vaccines and drugs and the development of diagnostic tests and surveillance, are essential to reduce $M$. leprae transmission and leprosy. In 2018, the WHO ${ }^{7}$ published the first Guideline for the Diagnosis, Treatment and Prevention of Leprosy based on scientific evidence. For all three dimensions covered, there are promising initiatives 13 yet the absence of fully performant serological tests with potential to be included in the routine of health services is still a limitation. The main diagnosis-related recommendation concerns the qualification of staff performing clinical diagnosis, confirmative bacilloscopy and histopathological tests. With regard to treatment, uniform multidrug-therapy (UMDT) using the same 3-drug regimen including rifampicin, dapsone and clofazimine for all leprosy patients, with a duration of treatment of 6 months for paucibacillary (PB) leprosy and of 12 months for multibacillary (MB) leprosy is recommended. Regarding disease prevention, single dose rifampicin (SDR) as post-exposure prophylaxis (PEP) comprising appropriate doses (600mg for adults) is recommended for domestic, neighbor and social contacts. Unfortunately, there is no diagnostic test available to detect $M$. leprae infection, identifying at-risk groups with reasonably high sensitivity. The titers of IgM and IgG antibodies against M. leprae vary according to the disease operational classification. IgM may be detected by enzyme-linked immunosorbent assays (ELISAs) based on phenolic glycolipid I (PGL-I) or natural disaccharide octyl bovine serum albumin (ND-O-BSA) as antigens; IgG response can be detected by an ELISA based on lipid droplet protein 1 (LID-1). A recent metanalyses showed no advantages in the overall estimated sensitivity for isolated LID-1 compared to PGL-I or ND-O-BSA 14. In terms of outlook, validating and introducing serological tests with anti-PGL-I and natural disaccharide octyl and lipid droplet protein 1 (NDO-LID) combination for field use might support the diagnosis 14 . Although additional biomarkers have been identified, validating and implementing their use remain challenging, and there is no reliable and rapid point-of-care (POC) test on the horizon. The main difficulty of existing tests is their unsatisfactory performance, especially for PB disease. This justifies the high expectations on developing more sensitive and specific tests based on T-cells and molecular technologies with a focus on PCR 15. In the longer term, the combination of improved imaging techniques, artificial intelligence and telemedicine might increase access to diagnosis. Complementing treatment, an important concern is the establishment of an effective drug resistance surveillance network, although current findings show a low prevalence of primary and secondary drug resistance 16.

Studies that seek to reduce treatment time or replace current medications are now underway 17. With regard to prevention and to complement the findings of the Leprosy Post-Exposure Prophylaxis (LPEP) program which demonstrated feasibility and acceptability of SDR-PEP across eight countries (Brazil, Cambodia, India, Indonesia, Myanmar, Nepal, Sri Lanka, and Tanzania) 18,19 as well as costeffectiveness 20, the benefits of adding BCG vaccination to SDR should be explored. Given at birth, BCG has been associated with an 80\% (95\%CI: 50\%-92\%) risk reduction of developing leprosy if SDRPEP is administered as post-exposure prophylaxis. BCG is particularly valuable for reducing the risk of $\mathrm{MB}$ cases while its effect on PB is less evident 21. Moreover, there is an active discussion on revaccination risks and benefits: while it may increase protection, it might cause accelerated manifestation of PB cases 22. Current evidence suggests maintaining BCG at birth until the development of a more effective option. A protein sub-unit vaccine has been developed by the Infectious Diseases Research Institute (IDRI) in Seattle, United States. LepVax as it is known, has completed phase I trials in the United States and will begin further trials shortly 23,24. Clinical trials under study with LepVax are also advancing, with the vaccine showing potential for both reducing the risk of illness and neural damage for infected patients 23 . The combination of immuno- and chemoprophylaxis would have a big effect on both infection and morbidity 13. It can be assumed that the preventive effect among contacts will increase when combining LepVax with chemoprophylaxis. LepVax also has the advantage over BCG that as a subunit vaccine it can potentially be given at the same time as antibiotics 24,25 . It is worth 
mentioning that both vaccination and PEP depend on extensive contact tracing 18,19. Another persistent challenge is the great number of patients with bacteriologically documented cure that present noticeable physical disabilities, affecting their economic, emotional and social life. Regardless of age, the risk of worsening physical disability after discharge from therapy is at least $30 \%$, after 10 years 21. In other words, thousands of former patients continue to require assistance in terms of care and prevention of disabilities.

Unlike several others NTDs, such as onchocerciasis and lymphatic filariasis, the procedures for verifying leprosy elimination are still to be developed. This is highly relevant as, although some regions are experiencing an increase in the number of diagnosed cases, many countries report very few cases, and possibly transmission has even ceased in some of them. Whether for reducing the burden of the disease or certifying its elimination, maintaining routine activities and establishing a robust surveillance-response system is crucial, but current infrastructure is insufficient in many places.

Interrupting $M$. leprae transmission and eliminating leprosy will depend on the decision of managers and funders of control programs, including Ministries of Health, to use all technologies available and recommended. Furthermore, partnerships and close collaboration between research institutions, international normative agencies, such as WHO, national health authorities, non-governmental organizations (NGOs), and funding partners are needed to implement and sustain innovations in routine health services and to progressively introduce the forthcoming new tools.

\section{Contributors}

Both authors contributed to the conception and elaboration of the article.

\section{Additional informations}

ORCID: Eliane Ignotti (0000-0002-9743-1856); Peter Steinmann (0000-0003-4800-3019).

\section{References}

1. World Health Organization. Global leprosy update, 2017: reducing the disease burden due to leprosy. Wkly Epidemiol Rec 2018; 93:44556.

2. Pan American Health Organization; World Health Organization. Policy on research for health. http://www.paho.org/hq/dmdocu ments/2009/CD49-10-e.pdf (accessed on Aug/2019)

3. World Health Organization. Handbook of resolutions and decisions of the World Health Assembly and the Executive Board. v. III, 19851992. 3rd Ed. Geneva: World Health Organization; 1993.

4. Smith WC, van Brakel W, Gillis T, Saunderson P. The missing millions: a threat to the elimination of leprosy. PLoS Negl Trop Dis 2015; 9:e0003658.

5. Coordenação Geral de Hanseníase e Doenças em Eliminação, Secretaria de Vigilância em Saúde, Ministério da Saúde. Plano integrado de ações estratégicas de eliminação da hanseníase, filariose, esquistossomose e oncocercose como problema de saúde pública, tracoma como causa de cequeira e controle das geohelmintíases, 2011-2015. Brasília: Ministério da Saúde; 2012.

6. Blok DJ, De Vlas SJ, Richardus JH. Global elimination of leprosy by 2020: are we on track? Parasit Vectors 2015; 8:548.

7. World Health Organization. Guidelines for the diagnosis, treatment and prevention of leprosy. Geneva: World Health Organization; 2018. 
8. Moet FJ, Pahan D, Schuring RP, Oskam L, Richardus JH. Physical distance, genetic relationship, age, and leprosy classification are independent risk factors for leprosy in contacts of patients with leprosy. Int J Infect Dis 2006; 93:346-53.

9. Valois EM, Campos FMC, Ignotti E. Prevalence of Mycobacterium leprae in the environment: a review. Afr J Microbiol Res 2015; 9:2103-10.

10. Han XY, Sizer KC, Velarde-Félix JS, Frias-Castro LO, Vargas-Ocampo F. The leprosy agents Mycobacterium lepromatosis and Mycobacterium leprae in Mexico. Int J Dermatol 2012; 51:952-9.

11. Nery JS, Ramond A, Pescarini JM, Alves A, Strina A, Ichihara MY, et al. Socioeconomic determinants of leprosy new case detection in the 100 Million Brazilian Cohort: a population-based linkage study. Lancet Glob Health 2019; 7:e1226-36.

12. Kawa N, Hanna E, Bizri AR.Transmissible dermatological diseases affecting Syrian refugees in Lebanon. Journal of Refugee \& Global Health 2019; 2:1-5.

13. Steinmann P, Reed SG, Mirza F, Hollingsworth TD, Richardus JH. Innovative tools and approaches to end the transmission of Mycobacterium leprae. Lancet Infect Dis 2017; 17:e298-305.

14. Espinosa OA, Benevides Ferreira SM, Longhi Palacio FG, Cortela DDCB, Ignotti E. Accuracy of enzyme-linked immunosorbent assays (ELISAs) in detecting antibodies against $\mathrm{Myco-}$ bacterium leprae in leprosy patients: a systematic review and meta-analysis. Can J Infect Dis Med Microbiol 2018; 2018:9828023.

15. van Hooij A, Fat EMTK, Richardus R, van den Eeden SJF, Wilson L, de Dood CJ, et al. Quantitative lateral flow strip assays as user-friendly tools to detect biomarker profiles for leprosy. Sci Rep Nature 2016; 6:34260.

16. Cambau E, Saunderson P, Matsuoka M, Cole ST, Kai M, Suffys P, et al. Antimicrobial resistance in leprosy: results of the first prospective open survey conducted by a WHO surveillance network for the period 2009-2015. Clin Microbiol Infect 2019; 25:646-7.

17. Hungria EM, Bührer-Sékula S, Oliveira RM, Aderaldo LC, Pontes MAA, Cruz R, et al. $M y$ cobacterium leprae-specific antibodies in multibacillary leprosy patients decrease during and after treatment with either the regular 12 doses. Front Immunol 2018; 9:915.
18. Steinmann P, Cavaliero A, Aerts ANN, Anand $\mathrm{S}$, Arif M, Cross H, et al. The Leprosy PostExposure Prophylaxis (LPEP) programme: update and interim analysis. Lepr Rev 2018; 89:102-16.

19. Barth-Jaeggi T, Steinmann P, Mieras L, van Brakel W, Richardus JH, Tiwari A, et al. Leprosy Post-Exposure Prophylaxis (LPEP) programme: study protocol for evaluating the feasibility and impact on case detection rates of contact tracing and single dose rifampicin. 2016. BMJ Open 2016; 6:e013633.

20. Tiwari A, Blok DJ, Suryawanshi P, Raikwar A, Arif M. Leprosy services in primary health care in India: comparative economic cost analysis of two public-health settings. Trop Med Int Health 2019; 24:155-65.

21. Ferreira SMB, Yonekura T, Ignotti E, Oliveira LB, Takahashi J, Soares CB. Effectiveness of rifampicin chemoprophylaxis in preventing leprosy in patient contacts: a systematic review of quantitative and qualitative evidence. JBI Database System Rev Implement Rep 2017; 15:2555-84

22. Duthie MS, Raychaudhuri R, Tutterrow YL, Misquith A, Bowman J, Casey A, et al. A rapid ELISA for the diagnosis of MB leprosy based on complementary detection of antibodies against a novel protein-glycolipid conjugate. Diagn Microbiol Infect Dis 2014; 79:233-9.

23. Duthie MS, Pena MT, Ebenezer GJ, Gillis TP, Sharma R, Cunningham K, et al. LepVax, a defined subunit vaccine that provides effective pre- exposure and post-exposure prophylaxis of $M$. leprae infection. NPJ Vaccines 2018; 3:12.

24. Duthie AM, Frevol A, Day T, Coler RN, Vergara J, Rolf T, et al. A phase 1 antigen dose escalation trial to evaluate safety, tolerability and immunogenicity of the leprosy vaccine candidate LepVax (LEP-F1 + GLA-SE) in healthy adults. Vaccine 2020; 38:1700-7.

25. Richardus R, Alam K, Kundu K, Roy JC, Zafar T, Chowdhury AS, et al. Effectiveness of single-dose rifampicin after BCG vaccination to prevent leprosy in close contacts of patients with newly diagnosed leprosy: a cluster randomized controlled trial. Int J Infect Dis 2019; $88: 65-72$.
Submitted on 03/Sep/2019

Final version resubmitted on 07/Jan/2020

Approved on 27/Feb/2020 